\title{
BENJAMIN E KRACAUER: ELEMENTOS DE UMA EPISTEMOLOGIA DE "TRAPEIROS"
}

Em I4 de abril de 1926 foi publicada no Frankfurter Zeitung uma seleção de aforismos de Walter Benjamin sob o título "Pequena iluminação" [Kleine Illumination]. O título, bem como a intermediação para a publicação dos textos, foi obra de seu amigo, Siegfried Kracauer, então funcionário do prestigiado jornal alemão. Em agradecimento, Benjamin escreve numa carta de 20 de abril de i926:

[...] por isso eu estou hoje já aqui com meu mais sincero agradecimento, não apenas pela colocação amigável e refletida de minhas coisas, mas também pela insistência e sucesso com que você soube ganhar para elas seus amigos na redação, não por último, porém, pelo título, que você concebeu. É algo maravilhoso para alguém que escreve ver-se e reconhecer-se em algum lugar organizado filologicamente de forma tão admirável, como ocorreu no caso desse título dado por você. Não posso de forma alguma mudá-lo, ele foi cunhado completamento a partir do centro dessas coisas, como eu nunca poderia ter encontrado melhor (Benjamin, 1987: 17).

Os aforismos publicados são onze daqueles que posteriormente fariam parte do volume sob o título de Rua de mão única. O belo título "Pequena iluminação", que tanto agradou Benjamin, não me parece simplesmente casual ou obra de uma inspiração repentina; ao contrário, o fato de ele ser "cunhado completamente a partir do centro dessas coisas" pode ser melhor compreendido caso tenhamos em mente a preocupação em comum dessas duas "personalidades" (volto a esse ponto mais abaixo) em relação às coisas pequenas 
ou a uma espécie de fenomenologia do detalhe: ao "fantasmagórico", aos "cacos", ao "extremo", ao "ornamento", ao "hieroglífico" - constelações conceituais que aparecem ora na obra de um, ora na de outro. A figura do trapeiro [Lumpensammler], cuja presença Benjamin destacou exaustivamente em suas análises da poesia de Baudelaire, parece-me então apropriada para nomear esse tipo de procedimento, pois as formas de analisar a sociedade no caso dos nossos autores implicaram aquele mesmo "passo" cambiante do colecionador de trapos que "se detém a cada instante para recolher o lixo no qual tropeça” (Benjamin, I99I, GS I: 583).

Uma discussão sobre essa especificidade procedimental extrapola, certamente, o âmbito de um artigo. Contudo, gostaria, ainda assim, de apontar algumas indicações da questão. Valho-me, para tanto, sobretudo da correspondência trocada pelos autores; do artigo que Kracauer escreveu em I928, intitulado "Sobre os escritos de Walter Benjamin"; das resenhas que Benjamin escreveu para o livro "Os empregados", intituladas "Um outsider faz-se notar" (I930) e "S. Kracauer, os empregados" (I930). ${ }^{\text {I }}$ De todo modo, a discussão não poderá ser conduzida totalmente sem referência a algumas outras de suas obras. Tais referências serão feitas, no entanto, de maneira reconhecidamente insuficiente, dado que a principal intenção é recolher elementos que contribuam para a percepção da mencionada inclinação aos objetos "marginais" e para tentativas de compreensão de tal inclinação, tanto em Kracauer como em Benjamin. A hipótese é de que não se trata simplesmente de um traço excêntrico, mas de uma adequação procedimental ao presente histórico.

Ressalvo que, neste artigo, procuro apontar para essa espécie de constelação. No entanto, isto não significa que não tenha havido consideráveis divergências entre os autores analisados. Aspectos dessas divergências podem ser encontrados, por exemplo, nas cartas que cada um trocou com Theodor Adorno, um interlocutor comum entre eles. Mas, por ora, deixo as polêmicas teóricas e/ou pessoais de lado, pois me interessa, sobretudo, o aspecto característico e peculiar das afinidades eletivas relacionadas a um determinado procedimento epistemológico.

No artigo "Sinais: raízes de um paradigma indiciário", Carlo Ginzburg analisa o que ele chama de um "modelo epistemológico" que teria emergido nas ciências humanas por volta do final do séc. XIX. Segundo tal modelo, os "resíduos", os "dados marginais", enfim, "pormenores normalmente considerados sem importância, ou até triviais, "baixos'” (Ginzburg, I989: I49-I50) forneceriam acesso "aos produtos mais elevados do espírito humano" (no caso específico de Sigmund Freud e a psicanálise, por exemplo). Não é meu objetivo aqui detalhar a discussão de Ginzburg e sua remontagem histórica desse "paradigma", no entanto, apenas o menciono rapidamente porque justamente essa espécie de "modelo epistemológico" é o que aproxima, a meu ver, Benjamin e Kracauer. 
No caso destes autores, não acredito que as raízes de tal modelo possam ser delegadas exclusivamente a Freud. Embora seja possível tecer similaridades entre os procedimentos, observo que Kracauer tinha ressalvas com relação ao método psicanalítico, e Benjamin, ao menos em sua interpretação da obra de Kafka, também se afasta cautelosamente da psicanálise. ${ }^{2}$

Por outro lado, ambos foram alunos de Georg Simmel, que Ginzburg, curiosamente, não menciona em seu artigo, mas que praticou, no âmbito da sua filosofia e sociologia, uma espécie de epistemologia que procurava apresentar "as relações que existem entre fenômenos mais externos, realistas, casuais e a potência mais ideal da existência, a mais profunda corrente da vida singular e a história" (Simmel, 2009 [1900]: I6).

Talvez esse contato em comum tenha sido um dos grandes responsáveis para a concepção de uma espécie de crítica materialista singular nos nossos autores. Um materialismo menos apegado à ideia de totalidade e mais afeito aos elementos marginais, no qual a "significância do tipo vital" pode se formar a partir do "insignificante", do "mais baixo" ou da "banalidade" (Simmel, I994 [I9Io]: 2II). De modo específico, embora terrivelmente resumido (considerando que este não é o ponto em discussão), poderíamos formular da seguinte forma: se, nas palavras de um contemporâneo de ambos, a "atitude existencial" da sociologia seria a "luta de classes", 3 Benjamin e Kracauer procuraram as configurações dessa situação existencial, sobretudo no que o último chamou de "manifestações de superfície" e não apenas na determinação da infraestrutura ecônomica.

A recepção de Simmel feita por Kracauer está registrada no livro escrito por este último e publicado de forma completa apenas recentemente, na nova edição de seus escritos coligidos. ${ }^{4} \mathrm{O}$ texto foi escrito ainda no período considerado por muitos comentadores como a juventude intelectual de Kracauer, mas revela uma acuidade de leitura e uma capacidade de síntese do pensamento múltiplo do autor de Filosofia do dinheiro, que dificilmente pode ser encontrada entre outros de seus intérpretes. De acordo com o "corte transversal" estabelecido por Kracauer para interpenetrar essa obra, "Todas as manifestações da vida espiritual estão em incontáveis relações uma com as outras, nenhuma é separável do contexto no qual se encontra com as outras" (Kracauer, 2004 [I9I9]: I50).

Em conformidade com essa percepção epistemológica do mundo, seria possível identificar uma dupla tarefa simmeliana: I) descobrir "os fios que se entrelaçam entre os fenômenos" (tarefa que é, em si mesma, infinita) e 2) "apreender o múltiplo como totalidade", pois "do princípio de que tudo está em relação com tudo, resulta imediatamente a unidade do mundo" (Kracauer, 2004 [I9I9]: I56).

Creio que a crítica cultural desenvolvida por Kracauer e Benjamin em seus textos alguns anos depois contempla, em alguma medida, essa dupla 
dimensão, embora talvez possamos reconhecer que os dois se dedicaram muito mais àquela primeira tarefa do que à segunda. Nesses trabalhos, o diagnóstico do presente, como processo de pensamento que separa para conhecer e transformar, sobressai a tentativa de apresentar uma totalidade articulada. ${ }^{5}$ Além disso, ambos os autores receberam muitas outras influências que de alguma forma contribuíram para cunhar seus procedimentos de atenção ao detalhe.

Benjamin, embora não tenha escrito nenhum texto de fôlego exclusivamente sobre Simmel, testemunhou explícita e implicitamente a influência que recebeu do antigo professor em diferentes momentos. Os rastros dessa influência aparecem, por exemplo, em sua leitura das grandes cidades modernas vinculada à alteração das formas de percepção e sentido. A ideia de que a visão, por exemplo, é mais sobrecarregada do que o ouvido no âmbito das grandes cidades aparece no texto A Paris do Segundo Império em Baudelaire (Benjamin, I99I [1938], vol. I: 539 e ss.) e corresponde ao procedimento epistemológico que tenta acompanhar os grandes processos sociais em suas consequências marginais ou micrológicas. Essa historicização radical da percepção, que alguns intérpretes benjaminianos leem como uma de suas maiores contribuições para as ciências humanas e sociais, não teria sido possível sem o conhecimento que o autor tinha da obra de Simmel que, na virada para o século XX, contribuiu de forma decisiva para operar uma guinada da filosofia para a dimensão concreta da vida social.

Em seu estudo sobre a concepção de modernidade em Simmel, Kracauer e Benjamin, David Frisby destaca justamente o ponto em comum relativo à presença da caracterização de moderno efetivada por Baudelaire: "transitório", "fugitivo", "contingente". O estudo reconhece a relevância da obra de Simmel nos dois últimos autores e pontua algumas recorrências na obra dos três pensadores, tais como o interesse pela dimensão de descontinuidade temporal e espacial típica das grandes cidades, pelas configurações estéticas e também o apego, que de igual modo compartilhavam, a uma forma determinada de teoria social que "não começa de uma análise da sociedade como um todo, ou de uma análise estrutural ou institucional", antes, "os três autores partem dos fragmentos aparentes da realidade social" (Frisby, I986).

Há, certamente, diferenças nas respectivas formas de como desenvolvem esses seus projetos de análise social, mas essa dimensão de perda de totalidade (ao menos daquela que se poderia obter de uma visada imediata) e a valorização do fragmentário aparecem nos três. Limito-me, no entanto, aos dois autores aqui analisados.

No caso específico de Kracauer, a perspectiva já pode ser reconhecida em uma discussão que desenvolveu sobre a Sociologia como ciência, livro que publicou em I92I, cuja tese central é a de que a quebra com a ideia de "uma 
época de sentido pleno", vinculada às visões religiosas do mundo, implicou o surgimento de um sujeito "que antes estava incluído na dança das configurações que preenchem o mundo", mas agora "ascende sozinho do caos como portador único do espírito, e diante de sua vista abre-se o império imenso da realidade" (Kracauer, 2006: I2) A tal sujeito cabe agora "avaliar a realidade ou pesquisar seu nexo de existência" (Kracauer, 2006: I3). Mas tal tarefa deve levar em conta o nível micrológico, pois, conforme a famosa formulação presente no texto O ornamento da massa [1927] "o lugar que uma época ocupa no processo histórico deve ser determinado de modo mais convincente a partir da análise de suas discretas manifestações de superfície do que dos juízos da época sobre si mesma" (Kracauer, 20I2 [I927]: 6I2): esta é a perspectiva que prevaleceria nos trabalhos escritos pelo autor durante a República de Weimar.

No que tange a Walter Benjamin, lembro apenas como exemplo desta subtração à tentativa de abarcar a totalidade de maneira imediata a sua fixação no objeto particular como procedimento para articular constelações sociais. Este traço, que Adorno, ao discutir os textos sobre Baudelaire, considerou pouco dialético, por isto uma renúncia à teoria que poderia esbarrar no positivismo, Benjamin tinha como a forma privilegiada de tornar "vivo" na nossa "experiência histórica" o objeto ou os bens culturais que nos são transmitidos como se fossem uma rigidez fechada (Adorno \& Benjamin, I995: 380). Ou seja, Benjamin toma a construção do objeto na "perspectiva histórica" como uma forma de atualizá-lo. Se as mediações teóricas ficam em segundo plano nessa perspectiva, também se deve ao fato de o autor desconfiar da ideia de totalidade.

Até aqui mencionei apenas a convergência que se refere ao procedimento de investigação de Kracauer e Benjamin. Ainda falta mencionar a familiaridade de perguntas que estava por detrás da imensa lista de objetos de interesse que compartilharam: cinema, literatura, a Paris do século XIX, memória, fotografia e, mais especificamente, no âmbito de cada um desses domínios, Charles Chaplin, Franz Kafka, Marcel Proust, o romance policial, as passagens subterrâneas etc. Mas, antes, gostaria de recuar um pouco a discussão para tentar expor algumas observações relacionadas à constelação de amizade entre os dois autores.

Utilizei propositalmente acima o termo personalidade para me referir aos dois intelectuais. O conceito, tão caro ao pensamento alemão no século XVIII e início do XIX, já foi definido como "o caminho da cultura" (Simmel apud Waizbort, 2000: II9) ou "o esforço para a unidade a partir do interno" (Weber, I986: 52I). Para Kracauer, que escreveu dois ensaios sobre o tema amizade: "Sobre a amizade" (I9I7) e "Pensamentos sobre a amizade" (I92I), a personalidade é uma condição indispensável para a constituição desse tipo de relação: 


\begin{abstract}
Apenas elas [personalidades] podem ser verdadeiramente amigas. Amizade ideal é, como nós antes de tudo queremos dizer, o encontrar-se de dois homens, de acordo com sua essência total resumida em eu-consciente (Kracauer, I980: 38).
\end{abstract}

Pois bem, embora correndo o risco de lidar com uma contradição difícil de ser solucionada (conforme procurarei explicitar um pouco mais adiante), insisto em utilizar o conceito, mesmo que necessite reforçar as aspas, pois creio que ele ajuda a entender as constelações histórica, subjetiva e social que contribuem para as convergências das obras dos autores.

\title{
PONTO DE VISTA SUBJETIVO
}

Não se sabe exatamente quando e onde Walter Benjamin e Siegfried Kracauer se conheceram, mas, de acordo com informação no volume de cartas entre os dois autores, o primeiro encontro teria se dado entre o fim de 1922 e no decorrer do ano de i923. A amizade, que não se desenvolveu sem perturbações, prevaleceria até a morte de Benjamin, em I940. Durante o exílio de ambos em Paris, a partir de I933, o contato se intensificou.

Quando Kracauer menciona a condição de personalidade como um pressuposto necessário para a amizade, ele certamente tem consciência das limitações do termo, que alguns anos mais tarde irá chamar de "conceito estúpido e idealista" (Kracauer, 20I I [I93I]: 674). No entanto, a amizade, de acordo com a citação acima, requer o esforço de formação da unidade correspondente à personalidade. Ou seja, apenas aqueles que se esforçam por configurar em si mesmos um campo de liberdade e indepêndencia face ao mundo da "cultura das coisas" (para utilizar um conceito de Simmel) são capazes de se relacionar nos termos ideais de uma amizade. Nessa característica Kracauer fundamenta a diferença entre amor e amizade: o amor "objetiva a mistura de toda a vida, enquanto o sentido da amizade está em harmonia com a personalidade" (Kracauer, I980: 39). Embora a distinção não possa ser rigorosamente delineada, o amor caracteriza-se por esse elemento de perder-se no outro, enquanto a "amizade verdadeira consiste no cultivo de disposições (Gesinnungen) semelhantes e pressupõe desenvolvimento conjunto nos âmbitos do conhecimento típico" (Kracauer, I980: 45 e ss.).

Do ponto de vista subjetivo, podemos afirmar, embora com cautela, que a relação entre os autores pode ser ancorada nessa perspectiva de sujeitos que, na contramão da história de coisificação e alienação reforçada de maneira radical após os anos I930 com a ascensão do nazifascismo e diante de inúmeras dificuldades materiais, buscavam, na medida do possível, conservar os fragmentos de suas personalidades. ${ }^{6}$

Certamente o termo é, portanto, anacrônico, no caso desses dois pensadores: fragmento e personalidade, de acordo com o sentido dado a esse 
último conceito (busca de unidade), são termos contraditórios. Mas é justamente esse "limiar" (para utilizar outra categoria relevante para seus modos de exposição) entre paradoxos que cunha suas obras de modo tão peculiar. Dito de outro modo, Benjamin e Kracauer procuraram nos rastros das novas formas sociais de fruição estética elementos que correspondessem ao que, na atualidade (conceito caro ao autor de O ornamento da massa), configuraria o humano [Mensch]. Unidade é exatamente o contrário dessa nova forma de Mensch, que, de acordo com a caracterização que Kracauer faz de Chaplin, "é sempre descontínuo, intercalado no organismo apenas em fragmentos" (Kracauer, 20II [I926], 6.I: 270).

A correspondência entre os amigos não é muito extensa, sendo que apenas quatro cartas endereçadas a Benjamin chegaram à posteridade. Mas sabemos também que durante o exílio em Paris (após I933) os encontros entre os autores eram muito frequentes. Os dois vivenciaram juntos a situação desesperadora de tentativa de conseguir os documentos necessários para sair da França e, pouco tempo antes do suicídio de Benjamin, em setembro de I940, encontravam-se quase diariamente em Marselha. Kracauer narraria posteriormente, em uma carta de I947, a lembrança daqueles dias:

Ele [Benjamin] acreditava que seu mundo estava aniquilado e medos pânicos asfixiaram nele a esperança; apenas Lili [esposa de Kracauer], a quem ele era muito afeiçoado, podia ainda dar-lhe apoio naquela época. Pouco tempo após ele, tentamos também novamente atravessar a fronteira espanhola, fomos enviados de volta e acampamos em Perpignan, onde ficamos sabendo que ele, que também não tinha sido aceito, tinha se suicidado. Nós mesmos estivemos muito perto de fazer o mesmo em Perpignan; eu, em todo caso. (Carta a E. e F.T. Gubler) (Belke \& Renz, I994: 96).

\section{ALGUMAS INDICAÇÕES SOBRE O CONTEXTO HISTÓRICO-SOCIAL}

Mas, conforme já adiantei, o termo personalidade deve, sob outro ponto de vista, ser utilizado no mínimo muito cautelosamente. De acordo com a minha tentativa de interpretação, o que mais aproxima Benjamin e Kracauer é justamente a radicalidade com que romperam com as definições clássicas do humano e seu caráter privado para se dedicar a uma reflexão, em grande medida desprovida de melancolia, sobre os novos sujeitos que se configuram na esteira das novas técnicas, tais como o cinema, a fotografia etc. Nessa reflexão, conceitos sociológicos ainda caros à sociologia e à filosofia até o início do século XIX, tais como povo, espírito, cultura, formação, interioridade, autenticidade etc. são substituídos por massa, distração.` Menciono, mesmo que muito resumidamente, que tal mudança conceitual não é simplesmente fortuita (como poderia parecer ao olhar contemporâneo), pois o que estava em jogo era, em alguma medida, a contestação de uma certa 
tradição predominantemente humanista e ligada aos valores burgueses que caracteriza o pensamento alemão até então, e que muitos coetâneos se recusaram a assimilar. ${ }^{8}$

Essas transformações no próprio modo de conceber o humano podem ser acompanhadas a partir do modo específico como ambos discutiram o tema da distração [Zerstreuung], ou seja, os novos modos de fruição estética.

Em um pequeno artigo de I926, "Culto da distração", Kracauer discute como o cinema e outras formas de entretenimento se relacionam com a vida nas grandes cidades e com as massas. Resumidamente, podemos dizer que a distração possuiria duas facetas: por um lado, ela tem a dimensão de alienação, na medida em que é um complemento à rotina dos trabalhadores, que desvia seus pensamentos da sua condição objetiva e impossibilita, assim, qualquer ação que pudesse conduzir a uma nova forma de organização social; por outro lado, a Zerstreuung, que pode ser traduzida tanto por distração como dispersão, é a única forma estética capaz de expor a atual forma de organização social. Assim, Kracauer reclama para a distração o seu "significado", ou seja, que ela exponha a desagregação [Zerfall], em vez de "colar as peças posteriormente e as oferecer como criação madura":

O fato de que as apresentações que pertencem à esfera da distração sejam uma mistura aparente tão semelhante ao mundo da massa da grande cidade; de que elas prescindam de todo nexo objetivo, exceto do cimento de sentimentalidade, a qual apenas oculta a carência, para torná-la visível; de que tais apresentações intermedeiem a milhares de olhos e ouvidos exata e francamente a desordem da sociedade - isto a capacita [a esfera da distração] a provocar e manter viva aquela tensão que deve preceder a mudança necessária. Não raro nas ruas de Berlim se é assaltado pela intuição de que um dia tudo arrebente repentinamente em dois. Os divertimentos, para os quais o público é impelido, também deveriam agir assim (Kracauer,20II: 2II).

Num mundo onde a "intimidade", a "privacidade", a "profundidade", em suma, os valores tipicamente burgueses perdem seu conteúdo, é necessário reconhecer a legitimidade, embora criticamente, das novas formas de cultura popular.

Benjamin certamente leu o artigo de Kracauer e, em seu famoso artigo “A obra de arte na era da reprodutibilidade técnica", escrito entre I935 e I936 e com versão publicada em I936, após inúmeras negociações, na revista do Instituto de Pesquisa Social (Zeitschrift für Sozialforschung), desenvolve, de modo muito semelhante, uma discussão sobre a distração e sua capacidade de apontar "para a dispersão, o desmanche, a desagregação (Zerfall)" (Gagnebin, 2005b: 264). Benjamin tem também em mente o perigo dos usos dos conceitos e valores idealistas pelos movimentos totalitários. Por isso sua discussão em relação à obra de arte e à reprodutibilidade técnica apoia-se em conceitos que se "se diferem de outros, na medida em que são completamente inutilizáveis para os objetivos do fascismo. Por outro lado, eles são úteis 
para a formulação de exigências revolucionárias na política da arte" (Benjamin, I99I: 435). Trata-se, pois, de abrir mão de critérios como de autenticidade (enquanto dado originário, único e portador de autoridade), eternidade e culto, por exemplo, para destacar o estágio de desagregação do mundo contemporâneo.

Uma discussão dos dois artigos não cabe nos limites deste texto, mas minha intenção é apenas apontar para a forma como o tema da distração/ dispersão, que, por si só, já testemunha a valorização do elemento fragmentário na epistemologia dos autores, faz parte da constelação histórico-social que ajuda a entender a convergência de suas discussões. E, se em tal constelação já não é possível utilizar o termo personalidade como conceito capaz de abarcar o comportamento dos sujeitos contemporâneos, é necessário, por outro lado, reunir em si mesmo as características correspondentes a ele para confrontar algumas tradições de pensamento de então.

Após esses apontamentos breves, retomo as perguntas que mencionei acima como aquelas que estariam por detrás das preocupações de Benjamin e Kracauer. Naquela mesma carta de 20 de abril de I926, em que Benjamin agradece a colocação dos textos sob o título de "Pequena iluminação", menciona uma série de artigos de Kracauer sobre objetos cotidianos publicados por aquele período no Frankfurter Zeitung, tais como "O piano", "Monóculo" e "Falso declínio do guarda-chuva". De acordo com a descrição de Benjamin: "Eles pintam o declínio da classe pequeno-burguesa em uma descrição notavelmente 'amável' de sua herança" [...] (Benjamin, ı987: I7).

E é a pintura desse declínio, sem perder de vista os outros inúmeros processos que estão por trás dele, e também suas consequências, que configura a grande questão em comum no caso desses dois autores. Ou seja, ambos estavam preocupados em acompanhar a passagem histórica de um mundo ainda pautado em valores mais ligados à interioridade, à formação [Bildung], ao "homem verdadeiro", à tradição, à eternidade, à concentração e à atenção para um mundo de valores provisórios, marcado pelas massas, pelo público, pela distração, pela desintegração [Zerfall], por uma "guinada para fora", conforme afirmou certa vez Kracauer.

E qual a melhor maneira de observar um mundo que se desintegra, senão a partir de suas ruinas, de seus escombros?

É assim que "os empregados" [die Angestellten], que, no original alemão compreende uma parcela específica dos trabalhadores, que não pode ser ligada nem à burguesia, nem ao proletariado, tornam-se um dos temas centrais dos textos de Kracauer para o Frankfurter Zeitung. Sua inclinação radical ao concreto, ao cotidiano, faz com que ele perceba esse grupo como um daque- 
les "extremos" a partir dos quais "a realidade pode ser deduzida" (Kracauer, 2006 [I929]: 213). Assim, telefonistas, secretárias, vendedores, datilógrafas, empregados dos setores de transportes, estenotipistas etc. ganham visibilidade a partir da exposição de suas vidas cotidianas. Não cabe aqui uma descrição detalhada da pequisa, mas, para me manter nos propósitos deste artigo, cito o final da resenha de Benjamin do livro:

\begin{abstract}
Assim este autor está lá no final, por direito, como um solitário [Einzelner]. Um descontente [Mißvergnügter], não um líder. Não um fundador, um desmancha-prazeres. E se queremos imaginá-lo totalmente por si na solidão do seu ofício e esforço, então vemos: um trapeiro matutino na alvorada que perfura, com sua bengala, os trapos de conversas e farrapos de falas, para, resmungando e teimoso, um pouco embriagado, lançá-los no seu carro, não sem deixar esvoaçar aqui ou ali no vento matinal, de maneira trocista, uma ou outra dessas chitas desbotadas: "humanidade", "interioridade", "profundidade". Um trapeiro, matutino - na alvorada do dia da revolução (Benjamin, I987: II2).
\end{abstract}

A bela analogia com esse trapeiro solitário certamente foi recebida com grande entusiasmo por Kracauer. Mais de duas décadas mais tarde (em 28 de agosto de I954), numa carta a Adorno, em que se discute o artigo deste último sobre Franz Kafka, ele mencionaria a comparação com um "trapeiro que chega ao raiar do dia e cata o lixo". Para Kracauer, é justamente o que faria também o escritor tcheco em sua literatura: "Kafka compreende o 'sistema' a partir de seus detritos (tal como alguém que revolve o lixo e compõe, somente para si, a partir dos trapos e entulhos desprezados, figuras belas)" 9 (Adorno \& Kracauer, 2008: 469).

Essa imagem do catador ou trapeiro, à primeira vista tão triste, não o é, ao menos não exclusivamente. Pistas desta questão estão já nas citações acima: na palavra "trocista" utilizada por Benjamin e, na expressão "figuras belas" de Kracauer. Mais um forte indício da convergência de pensamento desses autores é o de que, remexendo nesses objetos marginais reveladores de processos sociais e históricos mais amplos, eles encontram espaço para uma espécie de utopia, que tem uma dupla função: em primeiro lugar, a de não olhar de maneira saudosista para a formação social que poderíamos chamar (de maneira terrivelmente resumida) de mais comunitária e que se desintegra; em segundo lugar, a função de pensar as possibilidades oferecidas pelo mundo a partir da forma como ele é hoje. Esta dupla dimensão compreende a despedida de um mundo de "tradição doente", mas ainda "todo-poderosa". Se tal despedida é marcada pela "desorientação" provocada pelo enfraquecimento de valores sólidos, ela configura também a possibilidade de emancipação e liberdade daquele poder onipotente (ver, nesse ponto, leitura da interpretacão benjaminiana de Kafka presente em Gagnebin, i994: 66 e ss.).

Pontualmente, a problemática pode ser exemplificada, no caso de Kracauer, com a discussão desenvolvida no seu mais famoso ensaio, O ornamen- 
to da massa [1927]. Ali fica bem clara a perspectiva de que "o processo conduz a atravessar por meio do ornamento da massa, não voltar dele para trás" (Kracauer, 20I I, 5.2: 623). O argumento do autor é essencialmente iluminista, pois, para esse autor, a massa é justamente a possibilidade de libertar os indivíduos daquela configuração orgânica e unitária da natureza típica das "doutrinas mitológicas" e também do discurso fascista - embora a problemática não apareça diretamente, ela está em pauta e é reforçada pela opção de utilizar sem ressalvas o termo massa no lugar da ideia de povo [Volk], que estava na ordem do dia dos discursos contemporâneos. O autor aponta para duas dimensões do ornamento da massa: a positiva se refere a essa potencialidade de retirar o homem da sua "resplandescência orgânica" (ligada a essa dimensão da ideia de uma Kultur orgânica, ou comunidade integradora), mas a negativa se refere ao fato de que esse processo não é conduzido até o final, pois o homem passa de uma configuração natural para aquela inerente à abstratividade do pensamento econômico capitalista, que implica anonimidade. De maneira que falta ao processo que institui o ornamento da massa incluir o "fundamento humano". De todo modo, o ornamento teria de deixar "alegremente" atrás de si uma "ligação orgânica da natureza". Por isto a reflexão de Kracauer sobre ele reconhece sua "legitimidade parcial".

De maneira similar, embora sob um ponto de vista relativamente diferente, a visada de Benjamin sobre a reprodutibilidade técnica da obra de arte também reconhece uma dimensão positiva inerente à possibilidade de "descolar o reproduzido do âmbito da tradição", colocando a "massificação no lugar do acontecimento único". Nessa discussão, aparece de maneira pontual o problema que mencionei logo acima: para além do "valor de culto", da aura vinculada à "autenticidade" da obra de arte única, Benjamin aposta no "valor artístico" que se vincula à reprodutibilidade como possibilidade de se questionar a autoridade da "tradição". Essa potencialidade poderia conferir liberdade de apreciação e de concessão de sentidos aos indivíduos que se deparam com as novas formas artísticas. Por um lado, perde-se, portanto, aquilo que conferia um sentido mais universal ao "culto" da arte, sua significação religiosa, por exemplo - aqui a dimensão de desorientação. Por outro, possibilita-se uma autonomia potencial, pois a "reprodutibilidade técnica" permite "à reprodução encontrar o receptor em sua respectiva situação" (Benjamin, I99I: 438).

Embora tanto Siegfried Kracauer como Walter Benjamin estejam construindo suas reflexões fora do âmbito estritamente acadêmico, esse duplo caráter da nova ordenação do mundo social e seus reflexos sobre as manifestações artísticas e seu público não pode deixar de ser referido às discussões animadas pela sociologia alemã durante a República de Weimar em torno do par conceitual tornado célebre após a publicação da obra de Ferdinand Tönnies Comunidade e sociedade [Gemeinschaft und Gesellschaft], e também da opo- 
sição (igualmente clássica do pensamento alemão de então) entre cultura [Kultur] e civilização [Zivilisation]. Grosso modo, se comunidade e cultura representavam uma configuração social orgânica, solidária, na qual, conforme a já mencionada interpretação da obra de Simmel feita por Kracauer, uma unidade de pensamento possibilitaria a formação de uma personalidade plena, sociedade e civilização implicam a perda de sentidos conjuntos, mas, simultaneamente, e de forma paradoxal, a possibilidade de maior autonomia individual.

Benjamin e Kracauer apostaram de forma decisiva nessa dimensão do individual. Em "Experiência e pobreza", Benjamin formula a dicotomia de uma forma na qual podemos reconhecer aquela dupla função que mencionei mais acima:

Em suas construções, figuras e histórias a humanidade se prepara para sobreviver à cultura, caso assim tenha que ser. E o principal disto é que ela o faz rindo. Talvez esse riso soe aqui e ali bárbaro. Bom. Se, no entanto, o singular der às vezes um pouco de humanidade para aquela massa, ela o devolverá um dia com juros e juros sobre juros (Benjamin, I99I [1933], vol. 2: 219).

Para pensar essa dimensão contraditória da modernidade, tanto Charles Chaplin como Franz Kafka têm um lugar especial nas reflexões de nossos autores. Suas obras seriam similares a contos de fadas [Märchen]. A analogia aparece, curiosamente ou não, tanto em Benjamin como em Kracauer. Assim como nos contos de fadas, "Chaplin é bom e delicado e tem atenção a todas as criaturas" (Kracauer, 2004 [1928], 6.2: 34) e, para Benjamin, é justamente essa atenção às criaturas marginais (crianças, animais - conforme cita expressamente Kracauer em relação a Chaplin - e os condenados, os seres deformados do mundo do escritor tcheco que tanto despertam o interesse do autor de Passagens etc.) que seria uma das marcas características de Kafka. A semelhança das citações fala por si:

Se Kafka não rezava - o que não sabemos - era, no entanto, extremamente característico nele aquilo que Malebranche chama "a prece natural da alma": a atenção. E nela ele incluía todas as criaturas, como os santos em suas preces (Benjamin, I99I [1934], vol. 2: 432).

Incluir em suas reflexões "todas as criaturas": essa também é a intenção de Benjamin e Kracauer. A exigência benjaminina de uma "história dos vencidos" e a ideia "de que nada que alguma vez aconteceu deve ser dado como perdido pela história" (Benjamin, I99I [I940], vol. I: 696) e a pretensão inovadora da sociologia kracaueriana, por exemplo, de "introduzir a discussão pública", na medida em que seu trabalho "fale realmente" dos empregados, "que apenas com dificuldade podem falar sobre si mesmos" (Kracauer, 2008 [I929], p. 2I4) podem ser inseridas nessa perspectiva, dado que tanto "os vencidos" como os "empregados berlinenses" (de acordo com a investigação de Kracauer) fazem parte daquele grupo de "criaturas marginais". 
Ruínas, cujos destroços erguem-se contra o céu, aparecem às vezes duplamente bonitas em dias claros, quando a mirada em suas janelas ou extremidades superiores encontra as nuvens que passam. A destruição fortalece a eternidade desses destroços por meio do espetáculo transitório que ela inaugura no céu (Benjamin, 1987: 93).

A resenha de Kracauer, datada de 1928 , Sobre os escritos de Walter Benjamin, se refere a dois textos "Origem do drama barroco alemão" e "Rua de mão única". De acordo com o articulista:

Apesar de suas diferenças temáticas, ambas as obras estão unidas [zusammengehören] como expressão de um pensamento, que permanece estranho ao [pensamento] do tempo. Antes, os escritos talmúdicos e os tratados da Idade Média são seus parentes genealógicos. Pois, assim como neles, sua forma de exposição é a interpretação. Suas intenções são de modo teológico (Benjamin, I987: IOI).

O procedimento "monadológico" de Benjamin estaria em posição contrária à do "sistema filosófico" e sua generalização de conceitos (e, nesse ponto, não podemos esquecer que, numa certa ocasião, Benjamin, por sua vez, teria chamado Kracauer de "inimigo da filosofia", por conta do seu procedimento antissistemático e sua aversão ao idealismo) (Adorno, I986: 390).

De acordo com a resenha, a intenção de Benjamin seria "despertar o mundo de seu sonho", por isso os textos presentes em "Rua de mão única" seriam "ricos em detonações". As "pequenas partículas", que, nesses textos, "se tornam visíveis", apontam para essencialidades. Nessa característica estaria a peculiaridade do seu tipo de materialismo: para Kracauer, para quem a dialética teria como principal tarefa se afastar da "filosofia de totalidade" por meio de uma guinada em direção aos elementos mais concretos, cotidianos e pontuais da realidade social, o esquivamento da "essencialidade pura" concede grande valor aos aforismos benjaminianos.

Diante destes dois textos, Kracauer muito provavelmente também se identificou de forma especial com o procedimento benjaminiano de trabalhar com os resquícios do passado. Ele, que numa carta a Ernst Bloch datada de 29 de junho de 1926 menciona que o grande postulado da filosofia da história deveria ser que "nada deve ser esquecido e nada inesquecido deve permanecer sem transformação" (Bloch, I985: 28I), finaliza do seguinte modo a resenha:

Seu material próprio é o acontecido [Gewesene]; dos destroços resulta para ele o conhecimento. Aqui não é de modo algum a salvação do mundo vivo que é tomada como tarefa, antes, o meditante salva fragmentos do passado [...]. Se ele também não se demora no "reino dos vivos", busca das gravações das vidas vividas os significados lá depostos, que esperam insistentemente por receptores (Benjamin, I987: 105).

Se Benjamin prioriza, nesses textos, um mundo de esquecidos, do "acontecido" e seus "destroços", não é, no entanto, por conta de uma espécie 
de saudosismo. Em determinado ponto, Kracauer aponta explicitamente para a questão central que mencionei acima: "a soma de aforismos ['Rua de mão única'] denuncia conscientemente o fim da época individualista, ingenuamente burguesa" (Benjamin, I987: 104): novamente aparece nessa atenção ao detalhe, nesse procedimento epistemológico que dos destroços constrói o conhecimento, a tentativa de colher rastros de um mundo que se desintegra, não para reintegrá-lo, mas, ao contrário, para que esses rastros "inesquecidos" possam ser transformados.

Em seu agradecimento pela resenha, Benjamin escreve:

Tenho novamente agora grande alegria por sua resenha e quero escrever-lhe e agradecer-lhe por isso. Ela é, entre as existentes, a única que não apenas ilumina e expõe isto ou aquilo, mas conseguiu conceder-me um posto em uma ordenação. E como se deveria juntar a ela um selo de sorte, ela foi publicada exatamente no dia do meu aniversário (Benjamin, 1987: 65).

Esses "trapeiros" perceberam, ao colher as "heranças" de uma determinada configuração social, que na "alvorada do dia da revolução" era necessário abdicar de "um humano que foi expulso do pensamento contemporâneo, um humano que por direito não existe mais" (Kracauer, 20II [I93I], 5.3: 577). Trata-se, caso se queira assim formular, de um projeto político, em última instância. Mas um "projeto político" que não se realiza mais sobre as bases daquele humano consciente de sua individualidade, identidade, de sua personalidade. Deste modo, talvez a dimensão política do pensamento dos autores só possa ser melhor entendida caso tenhamos em mente a condição necessária para sua formulação: entender primeiro a forma que toma o mundo social sob seus pés.

Por isto procurei sublinhar, a partir desta espécie de epistemologia dos detalhes em Benjamin e Kracauer, sobretudo suas intenções de elaborar uma crítica do presente a partir das condições dadas, e não as idealizadas. Se, portanto, "quem quer mudar, deve estar informado sobre o que há para mudar" (Kracauer, 20I I [I927], 5.2: 623), então é necessário substituir o lamento em relação à totalidade de sentido perdida e a postura recriminativa das "pessoas cultas" diante dos fenômenos próprios do período da civilização ou sociedade, por uma constatação de que tais fenômenos "conferem forma a um material já dado". Para entender este novo "sistema", tanto Kracauer como Benjamin (que bem poderiam ter também como mestre em comum, ao lado de Georg Simmel, o escritor Franz $\mathrm{Kafka}^{\mathrm{Io}}$ ) lançam mão de um olhar sobre os limites, os detalhes e os detritos. 
ARTIGO | PATRÍCIA DA SILVA SANTOS

Patrícia da Silva Santos é doutoranda do Programa

de Pós-Graduação em Sociologia da Universidade de São Paulo (USP), onde é bolsista da Coordenação de Aperfeiçoamento de Pessoal de Nível Superior (CAPES). Realizou estágio na Ludwig-Maximilians-Universität (bolsista do programa CAPES/DAAD/CNPq). É autora de Racionalidade moderna e Franz Kafka (2007). Suas principais áreas de interesse são: teoria social, sociologia alemã e sociologia da cultura. 


\section{NOTAS}

I Todos esses textos estão reunidos no volume Walter Benjamin. Briefe an Siegfried Kracauer, mit vier Briefen von Siegfried Kracauer an Walter Benjamin (1987). As traduções, salvo indicação, são de minha autoria.

2 Kracauer menciona, em uma carta de I960, seu ceticismo na época de juventude em relação a Sigmund Freud (Belke \& Renz, I994: 4I). Na sua leitura de Kafka, Benjamin afirma "os dois equívocos fundamentais na tentativa de se aproximar do mundo de Kafka são a interpretação imediatamente natural e a interpretação imediatamente histórica: uma é representada por meio da psicanálise, a outra por Brod" (Benjamin, I99I, vol. 2: I98).

3 Ernst Lewalter apoia sua afirmação antes na postura weberiana e sua leitura do "capitalismo como o poder fatídico da vida moderna" do que na esperança "ingênua" que Marx teria depositado no proletariado (Lewalter, I93I: 463 e ss.).

4 Apenas o primeiro capítulo havia sido publicado em "O ornamento da massa", disponível recentemente em tradução brasileira (Kracauer, 2009).

5 Aqui tenho em mente a distinção de Gagnebin entre "dois traços essenciais do pensamento dialético": "O primeiro traço seria então essa concepção do pensamento como processo mediatizado e infinito de transformação; o segundo, a codeterminação recíproca entre particular e universal, a concepção de uma totalidade articulada, na qual partes e todo se definem mutuamente" (Gagnebin, 2005a: 92).

6 Mesmo sem entrar em detalhes, as polêmicas causadas pelos textos tanto de Kracauer como de Benjamin destinados à publicação na revista do Instituto de Pesquisa Social e as discussões decorrentes (nem sempre prazerosas de ler) podem ser acompanhadas na correspondência entre esses autores e Theodor Adorno, por exemplo. Creio que essas discussões dão uma ideia desse limiar contraditório entre sustentação da personalidade e condições históricas (Adorno \& Kracauer, 2008; Adorno \& Benjamin, 1994).

7 A literatura a respeito dos impasses da sociologia alemã na virada do século XX é extensa. Cito, por exemplo, Berking, que articula a crise da sociologia de então a partir 
de um confronto entre Massa e espírito, que o pensamento sociológico produzido durante a Republica de Weimar teria dificuldade em superar. Os modelos diletos dessa elite sociológica, tais como personalidade, formação, cultura, povo são confrontados pelos processos de massificação (Berking, I984).

8 Mitzman defende, por exemplo, a ideia de que a sociologia alemã seria marcada por suas raízes românticas (Mitzman, I966).

Um exemplo específico da dificuldade de formular as crises resultantes desse mundo de "passagem" é o caso de Thomas Mann, que, conforme Argelès descreve, teria fundado suas posições políticas em função da defesa da ideia alemã de cultura e comunidade (em oposição à civilização e sociedade) e por isso, sobretudo durante a República de Weimar, teria permanecido tributário de um conservadorismo político e social, que acreditava na educação como algo que deveria vir de cima: "Eu entendo democracia principalmente não como uma demanda e um colocar-se na mesma posição por baixo, mas como bem, justiça e simpatia por cima" (Mann apud Argelès, I994: 229).

9 Devo ao professor Leopoldo Waizbort a indicação da passagem e tomo aqui emprestada a sua tradução.

Io Nesse sentido, numa carta de 5 de dezembro de 1934 a Benjamin, Adorno mencionaria: "Até agora, todos nós permanecemos devedores de Kafka pela palavra solucionadora, Kracauer em maior medida" (Adorno \& Benjamin, I994).

\section{REFERÊNCIAS BIBLIOGRÁFICAS}

Adorno, Theodor. (1986). Der wunderliche Realist. In: Gesammelte Schriften I I. Frankfurt a. M: Suhrkamp, p. 388-408. Adorno, Theodor \& Kracauer, Siegfried. (2008). Briefwech sel I923-I966. Organizado por Wolfgang Schopf. Frankfurt a. M.: Suhrkamp.

Adorno, Theodor \& Benjamin, Walter. (1994). Briefwechsel I928-I940. Organizado por Henri Lonitz. Frankfurt a. M.: Suhrkamp.

Argelès, Daniel. (1994). Thomas Manns Einstellung zur Demokratie. Der Fall eines progressiven Konservativen. 
In: Gangl, M. \& Raulet, G. (orgs.). Intellektuellendiskurse der Weimarer Republik. Zur politischen Kultur einer Gemengelage. Frankfurt/M.: Campus, p. 22I-232.

Belke, Ingrid \& Renz, Irina. (1994). Siegfried Kracauer I8891966. Marbach: Deutsche Schillergesellschaft.

Benjamin, Walter. (I99I). Gesammelte Schriften. Frankfurt a. M: Suhrkamp (vol. I, 2 e 3).

Benjamin, Walter. (1987). Briefe an Siegfried Kracauer, mit vier Briefen von Siegfried Kracauer an Walter Benjamin. Marbach am Neckar: Marbach Schriften.

Berking, Helmut. (1984). Masse und Geist. Studien zur Soziologie in der Weimarer Republik. Berlim: Wissenschaftlicher Autoren-Verlag.

Bloch, Ernst. (1985). Briefwechsel: Siegfried Kracauer-Ernst Bloch I92I-I966. In: Briefe I. Frankfurt a. M.: Suhrkamp, p. 258-406.

Frisby, David. (1986). Fragments of modernity: theories of modernity in the work of Simmel, Kracauer, and Benjamin. Cambridge, MA: MIT Press.

Gagnebin, Jeanne Marie Gagnebin. (2005a). Do conceito de mímesis no pensamento de Adorno e Benjamin. In: Sete aulas sobre linguagem, memória e história. Rio de Janeiro: Imago. Gagnebin, Jeanne Marie. (2005b). Atenção e dispersão: elementos para uma discussão sobre arte contemporânea entre Benjamin e Adorno. In: Duarte, Rodrigo; Figueiredo, Virgínia \& Kangussi, Imaculada (orgs.). Theoria aesthetica. Em comemoração ao centenário de Theodor W. Adorno. Porto Alegre: Escritos, p. 253-266.

Ginzburg, Carlo. (1989). Raízes de um paradigma indiciário. In: Mitos, emblemas, sinais: morfologia e história. São Paulo: Companhia das Letras.

Kracauer, Siegfried. (2009). O ornamento da massa. São Paulo: Cosac Naify.

Kracauer, Siegfried. (2004-20I2). Werke I, 5 e 6. Frankfurt a. M.: Suhrkamp.

Kracauer, Siegfried. (1980). Über die Freundschaft: Essays. Frankfurt a. M.: Suhrkamp.

Lewalter, Ernst. (I93I). Die Moral der Soziologie. Ein Versuch über die Grundfragen der gegenwärtigen Soziologie. 
In: Neue Jahrbücher für Wissenschaft und Jugendbildung, ano 7, p. 452-465.

Mitzman, Arthur. (I966). Anti-progress, a study in the Romantic roots of German sociology. Social Research, 33, p. $65-85$.

Simmel, Georg. (2009). Philosophie des Geldes. Colônia: Anaconda Verlag.

Simmel, Georg. (I994). Soziologie der Mahlzeit. In: Das Individuum und die Freiheit. Essais. Frankfurt a. M.: S. Fischer.

Waizbort, Leopoldo. (2000). As aventuras de Georg Simmel. São Paulo: Ed. 34.

Weber, Max. (1986). Resultat: Konfuzianismus und Puritanismus. In: Gesammelte Aufsätze zur Religionssoziologie. Tübingen: Mohr, p. 512-535. 
BENJAMIN E KRACAUER: ELEMENTOS DE UMA EPISTEMOLOGIA DE “TRAPEIROS” Resumo
Proponho discutir a inclinação de Siegfried Kracauer e
ou detalhes e articular essa espécie de procedimento
epistemológico como resultado de uma adequação ao
presente histórico e também como um posicionamento
em relação às discussões sociológicas contemporâneas
aos autores. A correspondência entre ambos e as rese-
nhas que escreveram um sobre a obra do outro são o
principal material para a discussão. Embora não sistema-
ticamente, menciono também algumas obras dos autores
para indicar como sua análise social privilegia objetos
cotidianos e/ou fragmentos da vida social e algumas im-
plicações desse procedimento. BENJAMIN AND KRACAUER:
ELEMENTS OF AN EPISTEMOLOGY OF “RAGPICKERS" Abstract I propose to discuss Siegfried Kracauer's and Walter Benjamin's penchant to deal with marginal objects of investigation or details and to articulate this kind of epistemological procedure as a result of an adaptation to the historical present as well as a positioning concerning sociological discussions contemporary to the authors. The letters between both of them and the reviews that each one wrote on the works of the other are the main material for the discussion. Although not systematically, I mention also some works of the authors to indicate how their social analyze privilege everyday objects and/ or fragments of the social life and some implications of this procedure.
Palavras-chave

Siegfried Kracauer; Walter Benjamin; Epistemologia; Detalhe; Presente histórico.

\section{Keywords}

Siegfried Kracauer; Walter Benjamin; Epistemology; Detail; Historical present. 